\title{
Determinación de Antibióticos y Calidad Microbiológica de la Carne de Pollo Comercializada en Cartagena (Colombia)
}

\author{
Diofanor Acevedo ${ }^{*}$ Piedad M. Montero y José D.C. Jaimes \\ Universidad de Cartagena, Facultad de Ingeniería, Departamento de ingeniería de Alimentos, Avenida el \\ Consulado, Calle 30 No. 48-152. Cartagena, Bolívar-Colombia (e-mail: diofanor3000@gmail.com)
}

${ }^{*}$ Autor a quien debe ser dirigida la correspondencia

Recibido Mar. 12, 2014; Aceptado May. 30, 2014; Versión final recibida Jul. 8, 2014

\begin{abstract}
Resumen
El objetivo de este trabajo fue cuantificar los niveles de sulfametoxazol, norfloxacino, ciprofloxacino y lincomicina en pollo comercializado en el Mercado Bazurto, tiendas de barrio y supermercados de la ciudad de Cartagena (Colombia). Para esto se obtuvieron 10 muestras al azar de cada sitio de procedencia, con un total de 30 muestras para el estudio. Estas se empacaron en bolsas de polietileno de primer uso debidamente rotuladas para luego ser congeladas a $-18 \mp 1 \stackrel{\circ}{\circ} \mathrm{C}$. La cuantificación se realizó por cromatografía líquida de alta resolución (HPLC). Todas las muestras sobrepasan las cantidades mínimas de fármacos de acuerdo al Codex Alimentarius, exceptuando las pechugas de supermercado. Estas no sobrepasan los límites de sulfametoxazol y ciprofloxacino, y son las muestras que mantienen el umbral más bajo de detección para todos los análisis. Las únicas pechugas que cumplían con la legislación colombiana para recuentos microbianos fueron las procedentes de supermercados de cadena.
\end{abstract}

Palabras clave: antibiótico, HPLC, músculo de pollo, residuos

\section{Determination of Antibiotics and Microbiological Quality of Chicken Meat Commercialized in Cartagena (Colombia)}

\begin{abstract}
The aim of this study was to quantify the levels of sulfamethoxazole, norfloxacin, ciprofloxacin and lincomycin in chicken sold in Bazurto Market, local shops and supermarkets in the city of Cartagena (Colombia). For this 10 random samples from each site of origin were obtained, having a total of 30 samples for study. These samples were packed in new and not-used polyethylene bags properly labeled before being frozen at $-18 \mp 1^{\circ} \mathrm{O}$. Quantification was performed by high performance liquid chromatography (HPLC). All samples exceeded the minimum amounts of drugs according to Codex Alimentarius, except breasts supermarket. These are within the limits of sulfamethoxazole and ciprofloxacin and are the samples that presented the lowest detection threshold for all analyzes. The only breasts that met the limits of Colombian legislation for microbial counts were those sold by chain supermarkets.
\end{abstract}

Keywords: antibiotic, HPLC, muscle chicken, residues 


\section{INTRODUCCIÓN}

La utilización de antibióticos en los pollos debe ser segura para este y el consumidor, lo cual resulta beneficioso tanto en términos económicos como sanitarios al mejorar la rentabilidad. Los residuos de los antibióticos pueden llegar al consumidor a través de la cadena alimenticia produciéndole reacciones alérgicas, resistencia bacteriana, alteración de la flora bacteriana intestinal y producir problemas de comercialización debido al incumplimiento en las normas establecidas en distintos países (Guzmán et al., 2012; Molero-Saras et al., 2006). Los promotores de crecimiento básicamente actúan modificando la flora microbiana intestinal, provocando una disminución de los microorganismos causantes de enfermedades. También actúan reduciendo la flora normal que compite con el huésped por los nutrientes, conduciendo a una mejora en la productividad y reduciendo la mortalidad de los animales. Los antibióticos promotores del crecimiento pueden dar mejoras en la ganancia diaria de peso y en el índice de conversión de alimentos en un orden de $3-5 \%$ en pollos de engorde. Además de los beneficios económicos, las principales ventajas para los ganaderos son mayor uniformidad de crecimiento, estabilización de la flora intestinal en los animales, y mantenimiento de la salud en casos de estrés medioambiental en un grado que se puede decir que estos antimicrobianos promotores de crecimiento actúan profilácticamente, es decir reducen la morbilidad (Guzmán et al., 2012; Moreno-Bondi et al., 2009).

Los antibióticos presentan diversas propiedades que los diferencian químicamente entre sí, por lo tanto se requiere el uso de métodos de análisis específicos en cada caso. Tradicionalmente se han empleado ensayos microbiológicos, sin embargo, estos métodos presentan dificultades en la selectividad y especificidad para el análisis de antibióticos de una misma. En tal sentido, los métodos de análisis cromatográfico ofrecen una respuesta rápida, de alta sensibilidad y una separación eficiente de todos los análogos de una familia o grupo de antibióticos, lo cual permite que cada especie interaccione de manera particular con la fase móvil y estacionaria del sistema cromatográfico (Izquierdo et al., 2010). La industria avícola ocupa en el mundo un importante sitial dentro del sector agroindustrial gracias a los avances tecnológicos logrados en sus diferentes áreas (Morán, 2000). En tal sentido y tomando en cuenta los retos propios de los sistemas de producción, los antibióticos se han utilizado frecuentemente con fines terapéuticos, profilácticos y/o como promotores del crecimiento (Molero-Saras et al., 2006; Otero et al., 2001). Al margen de su reconocida utilidad, los antibióticos pueden o podrían ser utilizados de manera inapropiada, tanto en el ámbito médico humano como veterinario, siendo administrados en muchas ocasiones de forma irracional y en dosis inapropiadas, lo que conlleva a un conjunto de complicaciones en los humanos, lo cual a su vez crea la necesidad cada vez mayor de producir y usar nuevas drogas (MoleroSaras et al., 2006; Cancho-Grande et al., 2000).

Toda esta problemática, sumada a la necesidad de preservar la salud pública, conllevó a las autoridades sanitarias a establecer límites máximos de residuos sugeridos (LMRs) en los diferentes tejidos y especies de animales comestibles, cuyo estándar pretende establecer niveles de tolerancia mínimos para la seguridad alimentaria. En este sentido y para garantizar tales límites para un antibiótico de uso frecuente en la industria avícola, el propio fabricante recomienda no destinar las aves para consumo humano antes de siete días de finalizado el tratamiento. Sin embargo, para efectos de pretender garantizar la producción, tales tiempos con frecuencia no son respetados (Molero-Saras et al., 2006). Referente a esta normatividad el Codex Alimentarius en su Comisión de Límites Máximos de Residuos para Medicamentos Veterinarios en los Alimentos actualizado en la 35ª Sesión de la comisión del Codex Alimentarius Commission de Julio de 2012 estipuló los límites permisibles para antibióticos usados en alimentos, entre estos el pollo, lo cual sirve de base para algunos países que aun no poseen sus propios reglamentos acordes a su realidad, tal como sucede en Colombia.

En estudios anteriores ya se han realizado estudios de presencia de antibiótico en pollos en diferentes países. Guzmán et al., (2012) estudiaron la presencia de lincomicina como promotor de crecimiento en carne de pollo comercializado en supermercados de Cartagena (Colombia). Por otro lado Molero-Saras et al., (2006) analizaron residuos de enrofloxacina en tejido hepático y muscular de pollos beneficiados en el municipio de San Francisco del estado Zulia (Venezuela). En trabajo estos autores utilizaron como método para cuantificar, la cromatografía líquida de alta resolución, la cual dio resultados por encima de los límites permitidos de residuos (3810 ug/Kg de músculo pechuga) para la enrofloxacina miembro de la familia de las quinolonas. Finalmente Izquierdo et al., (2010) usando técnicas similares a la anterior realizaron la extracción de oxitetraciclina en carne de pollo, e hicieron estudios de rendimiento con aumento de la fase polar del solvente de extracción usando la misma. Por otro lado la calidad microbiológica de cárnicos es un tema de interés en la industria alimentaria (Wang et al., 2013). Considerando lo anterior, el objetivo de este trabajo fue cuantificar los niveles de sulfametoxazol, norfloxacino, ciprofloxacino y lincomicina de pollo comercializado en el Mercado Bazurto, tiendas de barrio y Supermercados de la ciudad de Cartagena (Colombia). 


\section{MATERIALES Y MÉTODOS}

\section{Muestras}

Se tomaron 10 muestras al azar de Supermercados, Mercado Bazurto y tiendas de barrio de la ciudad de Cartagena (Colombia) obteniendo un total de 30 muestras. La unidad de análisis estuvo conformada por una porción del músculo pectoral torácico (pechuga). Las muestras se empacaron en bolsas de polietileno de primer uso debidamente rotuladas para luego ser congeladas a $-18 \mp 1 \stackrel{\circ}{ } \mathrm{C}$.

\section{Técnica de detección}

Para la determinación de la presencia de residuos de sulfametoxazol, norfloxacino, ciprofloxacino y lincomicina en pechuga de pollo se utilizó la cromatografía líquida de alta resolución (HPLC), fundamentado en que estudios realizados en todo el mundo (Izquierdo et al., 2010; Molero-Saras et al., 2006; Pérez et al., 2001; San Martín et al., 2000) reportan que esta técnica es uno de los instrumentos con la más alta eficiencia y sensibilidad en la detección de estos residuos en tejidos de pollos. Molero-Saras et al., (2006), menciona que el HPLC es el instrumento con mayor versatilidad, y esto es debido a su alta aplicabilidad, sensibilidad y eficiencia en una gran gama de análisis cuantitativos, en los que refiere a las sustancias farmacológicas (antibióticos). De esta manera, las condiciones cromatográficas y preparación de estándares y muestras fue de acuerdo a metodología propuesta por Guzmán et al., (2012).

\section{Preparación de la muestra}

10 gramos de carne de pollo adicionadas con metanol al 5\% fueron sometidas por 30 min a microfiltración para asegurar la completa dilución del antibiótico (Baño de ultrasonido Cole Parner 8853). A continuación, fue centrifugada (Centrifuga BectonDickinson, USA) por $10 \mathrm{~min}$ a $5000 \mathrm{rpm}$. Se toma el líquido sobrenadante y se pasa a un beaker que contiene $1 \mathrm{~mL}$ de solución Carrez I y solución Carrez II. Esta mezcla se agitó y centrifugó por 10 minutos, el sobrenadante se pasó por un cartucho de extracción de fase solida C-18, previamente acondicionada. La extracción del analito en el cartucho fue realizada por elución con $5 \mathrm{~mL}$ de metanol. La solución de metanol fue filtrada e inyectada en el equipo de cromatografía. Todas las muestras fueron preparadas por triplicado.

\section{Condiciones cromatografías}

Las separaciones fueron desarrolladas en una columna de 250X4.6 mm Phenomenex Synergi Polar-RP Column (Phenomenex, USA). La fase móvil consistió en una mezcla de $85 \%$ de fosfato monobásico de sodio $\left(\mathrm{NaH}_{2} \mathrm{PO}_{4}\right) 20 \mathrm{mM}, 15 \%$ de acetonitrilo $(A C N)$ a un flujo de $1,5 \mathrm{~mL} / \mathrm{min}$ y una longitud de onda de detección de $210 \mathrm{~nm}$. El volumen de inyección de la muestra fue de $20 \mu \mathrm{L}$. El equipo utilizado fue un cromatógrafo líquido (BAS SS60) equipado con una bomba ternaria e inyección manual y un detector UVVIS (BAS) de longitud de onda variable.

\section{Validación metodológica-Técnicas de HPLC}

El coeficiente de correlación lineal fue de 0,985 para sulfametoxazol, 0,986 para norfloxaciono, 0,985 para ciprofloxacino y 0,988 para lincomicina. El límite de cuantificación en el músculo de pollo fue de 0,0120 mg/g para sulfametoxazol, $0,0445 \mathrm{mg} / \mathrm{g}$ para norfloxaciono, $0,0567 \mathrm{mg} / \mathrm{g}$ para ciprofloxaciono y 0,0472 para lincomicina. Los límites de detección en el músculo de pollo fue de 0,0036 $\mathrm{g} / \mathrm{g}$ para sulfametoxazol 0,0109 $\mathrm{g} / \mathrm{g}$ para norfloxaciono, $0,0182 \mathrm{~g} / \mathrm{g}$ para ciprofloxacino y 0,0168 $\mathrm{g} / \mathrm{g}$ para lincomicina. Los promedios de recuperación obtenidos fueron para sulfametoxazol: 74-85\% RSD 5,86\%; norfloxaciono: 67-85\% RSD 5,82\%; ciprofloxacino 69-89\% RSD $8.66 \%$ y $78-90 \%$ RSD 6,66\% para lincomicina.

\section{Pruebas microbiológicas}

Los recuento de aerobios, coliformes totales y fecales, $S$. aureus y Salmonella se realizaron de acuerdo a indicaciones de la Norma Técnica Colombiana 1325 (2008) y se expresan como Log de UFC/g. Los resultados se muestran como promedios de pruebas por triplicado de los datos obtenidos para cada sitio de muestreo.

\section{RESULTADOS Y DISCUSIÓN}

En la Tabla 1 se muestran los resultados arrojados por el HPLC para cada tipo de antibiótico de acuerdo a la zona de muestreo, y adicionalmente se comparan con el índice de permisibilidad para cada tipo de fármaco según la normatividad que establece el Codex Alimentarius en su Comisión de Límites Máximos de 
Residuos para Medicamentos Veterinarios en los Alimentos actualizado en la 35a Sesión de la comisión del Codex Alimentarius Commission de Julio de 2012. En cuanto al método por HPLC se considera que es relativamente costoso pero es muy importante su utilización debido a que es altamente eficiente y sensible por los resultados que confirman la presencia y cantidad de antimicrobianos presentes en las muestras analizadas además de ser avalado por el Codex Alimentarius. Además es importante controlar una probabilidad de riesgo para los consumidores, ya que varios autores señalan que el consumo continuo de antibióticos, aún en bajas concentraciones, permite el desarrollo de cepas resistentes que pueden llegar a inducir patologías y un conjunto de complicaciones en los humanos, entre las que se destacan: infecciones múltiples, retraso en la identificación del agente causal y aparición de gérmenes antibiótico-resistentes (Molero-Saras et al., 2006; Navarro et al., 2001; Orden y Fuentes, 2001; Cancho-Grande et al., 2000; Sumano y Gutiérrez, 2000; Rankin, 1998).

Tabla 1: Antibióticos obtenidos en pollo por cada sitio de muestreo

\begin{tabular}{|c|c|c|c|c|}
\hline Lugar muestreo & Sulfametoxazol $(\mathrm{ppm})$ & $\begin{array}{c}\text { Norfloxacino } \\
(\mathrm{ppm})\end{array}$ & Ciprofloxacino (ppm) & $\begin{array}{c}\text { Lincomicina } \\
(\mathrm{ppm})\end{array}$ \\
\hline Mercado Bazurto & $291,98 \mp 4,56$ & $3450,43 \mp 8,45$ & $180,56 \mp 4,89$ & $4,098 \mp 0,67$ \\
\hline Tienda de Barrio & $250,23 \mp 1,89$ & $3200,45 \mp 8,45$ & $156,34 \mp 8,34$ & $2,06 \mp 0,47$ \\
\hline Supermercado & $90,45 \mp 2,03$ & $200,37 \mp 6,78$ & $20 \mp 0,35$ & $1,078 \mp 0,46$ \\
\hline Permitido & 100,0 & 100,0 & 100,0 & 200,0 \\
\hline
\end{tabular}

\section{Sulfametoxazol}

De acuerdo con la Tabla 1 se puede decir que para Sulfametoxazol exceptuando a las pechugas procedentes de supermercado, la cantidad de residuos están fuera de los límites máximos permitidos por el Codex Alimentarius, ya que las pechugas de Mercado Bazurto y tiendas de barrio superan las 100 ppm de sulfamidas en general que permite la normatividad. En otros estudios Lobo et al., (1999), detectaron niveles de oxitetraciclina superiores a $600 \mathrm{ppm}$, a pesar de las regulaciones en cuanto a LMRS para este antibiótico en la Unión Europea. Estos autores indican que no existe control en cuanto al manejo de ese tipo de medicamentos, y que los organismos oficiales no llevan a cabo programas de detección de residuos químicos en los productos alimenticios de origen animal.

\section{Norfloxacino}

Las quinolonas son los antimicrobianos que han tenido un mayor desarrollo en los últimos años. Después de obtenerse el ácido nalidíxico, en 1962, se desarrollaron varios compuestos con características muy similares, que solo se establecieron como antisépticos urinarios, y que constituyeron la primera generación de quinolonas, hasta que en 1978, mediante la adición de un grupo piperacinil en posición 7 y un átomo de flúor en posición 6 comenzó a desarrollarse un conjunto de agentes antibacterianos llamados piperacinil fluoroquinolonas o simplemente fluoroquinolonas. El primero de ellos fue el norfloxacino, quinolona de segunda generación (Cúe et al., 2005). Para el caso de las muestras con residuos de norfloxacino, todas estuvieron fuera de los límites permitidos por el Codex Alimentarius, ya que para quinolonas de segunda generación como el norfloxacino las muestras no deben sobrepasar las 100 ppm. Pero aun así el valor más bajo observado fue para el pollo de supermercado con 200,37 ppm. Otros investigadores han reportado residuos de antibióticos en carne fresca para consumo humano. Alvarado et al., (2008) reportó residuos de oxitetraciclina en carne de bovinos procedentes de la misma zona, demostrando la existencia de residuos de oxitetraciclina en carnes destinadas al consumo humano, por encima de los límites máximos sugeridos por la FDA y el Codex Alimentario. De las muestras que resultaron positivas a la presencia de residuos, en el $96 \%$ de las mismas se obtuvieron niveles de residuos superiores a $250 \mathrm{ppm}$, valor establecido como LMRS para carne de bovino de consumo humano.

\section{Ciprofloxacino}

En cuanto a los resultados del ciprofloxacino, se sobrepasan los límites máximos permitidos por el Codex Alimentarius para las muestras de Mercado Bazurto y la tienda de barrio, pero los niveles para el supermercado estuvieron dentro de los límites permitidos. Estos resultados se comparan con los del trabajo de Molero-Saras et al., (2006), quienes determinaron la presencia de residuos de enrofloxacina (otra quinolona de segunda generación) en los tejidos (músculo e hígado) de pollos beneficiados en cuatro plantas ubicadas en el municipio San Francisco del estado Zulia, Venezuela. Tomaron pollos directamente de los expendios ubicados en cada planta durante cinco días consecutivos, dando un total de veinte pollos. Estos autores también realizaron el análisis de las muestras a través de cromatografía líquida de alta 
resolución (HPLC), y al igual que en esta investigación la presencia de enrofloxacina se encontró por encima de los Límites Máximos de Residuos sugeridos por la FDA, Codex Alimentario y EMEA, al alcanzar 3810 ppm en pechuga, lo cual abre una duda razonable en relación a la salud de los consumidores de pollo. Por otro lado Anadón et al., (1995) también reportó la presencia de enrofloxacina en pollos, pero en niveles tres veces inferiores a los señalados por el estudio anterior. Según Molero-Saras et al., (2006) las diferencias obedecen a condiciones experimentales y controladas de un ensayo contra una realidad del campo venezolano.

Otero et al., (2001) llegaron a la conclusión que se necesita prohibir el uso de premezclas que contengan enrofloxacina o ciprofloxacina, y sugieren que estos fármacos debe ser utilizado exclusivamente en problemas específicos en la clínica de aves, debido a que el uso de antibióticos como aditivos en el alimento para aves dirigidas al consumo humano puede resultar en el desarrollo de resistencia al aditivo y que esta condición puede ser transferida al consumidor por vía de la cadena alimentaria.

\section{Lincomicina}

Las muestras que presentaron mayor concentración de lincomicina fueron en su orden Mercado Bazurto y tienda de barrio. Todas las muestras analizadas en esta investigación, contienen residuos de lincomicina y están por encima del límite establecido por Codex Alimentarius fijado en 200 ppm. Resultados similares fueron obtenidos por Guzmán et al., (2012), quienes en su estudio determinaron y cuantificó la presencia del lincomicina en carne de pollo como promotor de crecimiento comercializado en almacenes de cadena en Cartagena de Indias. Los autores escogieron cuatro marcas, a las cuales se les realizó análisis mediante el uso de cromatografía líquida para determinar cual de ellas contenía en mayor proporción del antibiótico. Sus resultados mostraron presencia del promotor de crecimiento en todas las marcas de pollo.

\section{Análisis microbiológicos}

Tabla 2: Análisis microbiológico a pechugas de pollos analizadas

\begin{tabular}{|c|c|c|c|c|c|}
\hline Lugar muestreo & Aerobios & $\begin{array}{c}\text { Coliformes } \\
\text { totales }\end{array}$ & Coliformes fecales & S. aureus & Salmonella \\
\hline Mercado de Bazurto & 7,20 & 7,71 & 6,50 & 2,0 & 0,0 \\
\hline Tiendas & 5,90 & 7,43 & 5,30 & 2,0 & 0,0 \\
\hline Supermercado & 2,0 & 0 & 0,0 & 0,0 & 0,0 \\
\hline Máximo Permitido & 5,0 & 2,0 & 2,0 & $<2,0$ & 0,0 \\
\hline
\end{tabular}

En la Tabla 2 se pueden observar los resultados de recuento total de Aerobios, Coliformes totales y fecales, S. aureus y Salmonella expresados como Log de UFC/g que se realizaron a las pechugas de pollo. Según la Tabla los pollos procedentes de supermercado son los únicos que se encuentran dentro de los rangos estipulados por la Norma Técnica Colombiana 1325 (2008) para índice máximo permisible para nivel de buena calidad en cárnicos frescos. Los malos resultados de las demás pechugas son valores probablemente relacionados con las malas prácticas higiénicas durante su almacenamiento y venta.

\section{CONCLUSIONES}

Todas las muestras sobrepasan las cantidades mínimas de sulfametoxazol, norfloxacino, ciprofloxacino y lincomicina para músculo de pollo de acuerdo a los índice de permisibilidad para cada tipo de fármaco según la normatividad que establece el Codex Alimentarius en su Comisión de Límites Máximos de Residuos para Medicamentos Veterinarios, exceptuando las pechugas provenientes de supermercado que no sobrepasan los límites de sulfametoxazol y ciprofloxacino, y son las muestras que mantienen el umbral más bajo de detección para todos los análisis. Para las muestras que no cumplen con la norma las causas pueden ser debidas a que el tiempo de espera para la eliminación de antimicrobianos no se cumple en las avícolas que proveen pollo a los lugares de comercialización o la dosis administrada es muy alta. De acuerdo a su procedencia las pechugas presentan diferencias claras en cuanto a su calidad microbiana. Los recuentos microbianos inferiores, y los únicos que cumplían con la legislación colombiana se encontraron en pechugas de supermercado, lo que hace pensar que las procedentes de la central de abasto y las ventas ambulantes presentan malas prácticas higiénicas durante su almacenamiento y venta.

\section{REFERENCIAS}

Alvarado, S.M., Ascanio, E. y C. Mendez, Determinación de residuos de oxitetraciclina en muestras De tejido bovino destinadas al consumo humano, Rev. Fac. Cienc. Vet., 49(2), 73-79 (2008). 
Anadón, A. y otros siete autores, Pharmacokinetics and residues of enrofloxacin chickens, Am. J. Vet. Res.: 56(4), 501-506 (1995).

Cancho-Grande, B., M.S. García-Falcón y J. Simal-Gándara, El uso de los antibióticos en la alimentación animal: Perspectiva actual, Cien. Tecnol. Alim: 3, 39-47 (2000).

Comisión del Codex Alimentarius, Límites Máximos de Residuos para Medicamentos Veterinarios en los Alimentos (2012), ftp://ftp.fao.org/codex/weblinks/MRL2_s_2012.pdf. Acceso 2 de noviembre (2013).

Cué, M., M. Morejón y R. Salup, Actualidad de las quinolonas, Rev Cub. Farmacología: 39(1), 1-1 (2005).

Guzmán-Carrillo, L.E., C. Espitia-Yanez y L. Berthel, Presencia de lincomicina como promotor de crecimiento en carne de pollo comercializado en supermercados de Cartagena, Colombia, Vitae: 19(1), 328330 (2012).

Izquierdo, P. y otros cinco autores, Extracción de Cxitetraciclina en carne de pollo: estudios de rendimiento con aumento de la fase polar del solvente de extracción: Revista Científica: 20(4) 430-435 (2010).

Lobo, M. y otros seis autores, Vigilancia de residuos de tetraciclina, oxitetraciclina y clortetraciclina y sus 4 epímeros en corderos destinados a consumo humano, Rev. Toxic., 16, 156-161 (1999).

Molero-Saras, G.L. y otros cinco autores, Residuos de enrofloxacina en tejido hepático y muscular de pollos beneficiados en el municipio San Francisco del estado Zulia, Venezuela, Revista Científica: 16(6), 629-633 (2006).

Morán, E., Nutrición, Genética e Interacciones de Enfermedades en la Producción Moderna de Pollos de Carne, Avic. Prof: 18(2), 33-36 (2000).

Moreno-Bondi, M. y otros tres autores, An overview of sample preparation proceduresfor LC-MS multiclass antibiotic determination in environmental and food samples, Anal Bioanal Chem: 395(4), 921-946 (2009).

Navarro, N.M. y otros tres autores, Resistencia a los antibióticos en cepas comunitarias y hospitalarias de Staphylococcus aureus, Bol. Clin. Hosp. Infant: 18(8), 9-13, (2001).

NTC 1325, Instituto Colombiano de Normas Técnicas y Certificación (Colombia), Establece los requisitos y los métodos de ensayo que deben cumplir productos cárnicos procesados no enlatados. Quinta Actualización, Bogotá, Colombia (2008).

Orden, G.J.A. y L.R. Fuentes, Repercusiones en la salud pública de la resistencia a quinolonas en bacterias de origen animal, Rev. Esp Salud Pública: 75(4), 20-36 (2001).

Otero, J.L., N. Mestorino y J.O. Errecalde, Enrofloxacina una fluorquinolona de uso exclusivo en veterinaria (parte II): farmacocinética y toxicidad, Anal. Vet.: 21(1), $42-49$ (2001).

Pérez, J.A. y otros cuatro autores, Residuos de sustancias inhibidoras en carnes, Rev. Esp. Salud Pública: 3, 1-8 (2001).

Rankin, S.C., Multiple antibiotic resistance in Salmonella, Vet. Rec.:143, 698-699 (1998).

San Martín, B. y otros tres autores, Comparación del método microbiológico con cromatografía de alta resolución (HPLC) en la detección de residuos de quinolonas y fluoroquinolonas en músculo de peces Salmonideos, Avances en Cien. Veterinaria: 15(1-2), 20-35 (2000).

Sumano, H. y L. Gutiérrez, Problemática del uso de Enrofloxacina en la Avicultura en México, Vet. México: $1(2), 137-145(2000)$.

Wang, X.H. y otros cuatro autores, Effects of inoculating Lactobacillus sakei starter cultures on the microbiological quality and nitrite depletion of Chinese fermented sausages, Food Control: 32(2), 591-596 (2013). 